\title{
21. The gender division of housework and child care Oriel Sullivan
}

\section{INTRODUCTION}

Why is the division of housework and child care important to the sociology of the family? This question cannot be addressed without first distinguishing between housework and child care, which in much of the early history of research into the division of labour were often lumped together into the undifferentiated category of 'unpaid work'. ${ }^{1}$ On the one hand, research on housework has yielded important insights into couple gender relations and, in particular, into the ways in which heterosexual couples negotiate, bargain over, and argue about the division of an undesirable activity (housework) in a situation of unequal gender power. On the other hand, the study of the parental division of child care has contributed to our understanding of changes over time in parental input into the daily lives of their children, the ways in which mothers and fathers divide up different child-care activities, and the impact of the time parents spend with their children on child outcomes.

The gender division of housework and child care is one of the most critical determinants of both the work-life balance and the life chances of women and men in couples (see also Grunow in this volume). While the gender pay gap has recently received considerable media attention, the focus on paid work can obscure the contributions of housework and care to this gap. In a context in which both women and men are expected to participate in the labour market, the overall gender division of labour (both paid and unpaid) within couples determines to a large extent what the outcomes of this participation will be. The traditional and ongoing expectation that women will be responsible for the burden of domestic labour and care can make it more difficult for women to acquire employment skills and experience, which can, in turn, result in a pension gap that mirrors the gender pay gap, and that continues to have an impact on women's quality of life and life chances into older ages.

This is the wider context in which the theoretical discussions of how couples negotiate the division of household chores and care take place. These discussions have been predominantly, although not exclusively, framed by a hetero-normative vision of 'coupledom'; i.e., based on the implicit assumption of a heterosexual couple living with their children (see also Evertsson et al. in this volume). In this chapter I aim to show patterns of convergence in the gender division of housework and child care, while seeking to understand the processes involved in these long-term, cross-generational trends.

\section{THEORETICAL PERSPECTIVES}

The underlying assumption of traditional economic models of the division of labour is that men and women in couples divide their paid and unpaid work rationally, according to their respective earned income potential (e.g., Becker 1981). To paraphrase, these models posit that in a gender-unequal marketplace, men earn more than women on average, primarily because 
of women's childbearing and childrearing responsibilities, and this 'economic rationality' explains the unequal gender division of labour. Economic bargaining theory extended these models by introducing a bargaining element into the equation. Proponents of this perspective argued that women and men in couples negotiate and bargain over who gets to do the least desirable tasks, based on the assumption that housework is among the least desirable of all activities (Lundberg and Pollack 1996; Sorensen and McLanahan 1987 - this assumption has been confirmed by the results of surveys in which respondents are asked to rate their enjoyment of daily activities; Gershuny 2019). As this bargaining takes place in a context of unequal power between women and men, the less economically powerful partner (i.e., the woman) usually ends up doing more unpaid work.

The assumption of an economically rational division of labour, even when mediated by economic bargaining under conditions of unequal power between women and men, has, however, been criticised by feminist researchers (e.g., Berk 1985; Hochschild and Machung 1989). It has, for example, been pointed out that those who do the bulk of housework and child care (i.e., women) - in particular, those who spend time out of the labour force while on maternity leave or who engage in part-time employment - have fewer chances to develop their employment skills and experience, which can negatively affect their career/employment trajectories, and, hence, their potential earnings (see Sullivan et al. 2018). Therefore, doing unpaid household work is as much a cause of economic inequality as it is an effect. In light of continuing cross-time and cross-national gender inequality in the performance of housework and care, an alternative theoretical perspective, the gender perspective, has gained substantial traction. According to this perspective, gender itself - as constituted both ideologically and in practice ('doing gender'; West and Zimmerman 1987) - is an important determinant of who does what type of paid and unpaid work, including care tasks. The gender perspective is supported by the consistent research finding that even in couples in which the woman earns the same or more than her male partner, the woman continues to do more housework and child care than her male partner.

\section{LANDMARK RESEARCH FINDINGS}

\subsection{The Sociology of Housework: Economic Bargaining versus Gender}

The idea of housework as a topic of sociological enquiry has its roots in the second wave of feminism in the 1970s. Because housework is generally perceived negatively, which partner does the housework has long been regarded in the sociological literature as an important indicator of marital power; a research tradition dating back to the work of Blood and Wolfe (1960). The research of Oakley (1974) in the United Kingdom (UK), and of Berk (1985) and Hochschild and Machung (1989) in the United States (US), highlighted the boring, repetitive, and isolated nature of housework, and provided important gender-based explanations for why housework became a feminised task.

The early findings of quantitative empirical research (e.g., Brines 1994; Greenstein 2000) broadly supported the arguments of economic bargaining theory by showing that there was a negative linear dependence between relative spousal earned income and the amount of housework done. However, highly influential evidence was also found for a gender deviance neutralisation effect - a term coined by Bittman et al. (2003). Brines argued that while the 
housework hours of wives and husbands largely confirmed the assumptions of conventional economic bargaining theory, husbands who were economically dependent (particularly those in low-income households and the long-term jobless) did less housework than others. These analyses lent strong support to gender theory by seeming to demonstrate that in certain structural situations, the power of gender could override the power of money.

Indeed, qualitative research conducted in Britain and the US during the 1980s had already begun to document behaviours among men in certain economic situations that resonated with the idea of gender deviance neutralisation. British studies showed that working-class men who had lost their economic power in the household by losing their paid employment tended to emphasise their gender-normative role by not contributing to the housework, regardless of the employment status of their female partner (Morris 1985). In the US, Hochschild and Machung (1989) reported similar findings; among couples where the husband earned less than his wife, none of those husbands shared the housework, while among those couples where the husband earned the same as or more than his wife, between a fifth to a third of husbands shared the housework.

A complementary hypothesis of gender deviance neutralisation among breadwinner wives emerged from the findings of Greenstein (2000), but subsequent studies have not produced a unanimous verdict on the importance of gender deviance neutralisation vis-à-vis economic bargaining. Killewald and Gough (2010), for example, found no relationship between spousal relative earnings and women's housework hours; while Gupta (2007) and Gupta and Ash (2008) concluded that women's absolute, rather than their relative earnings determined their housework hours; dubbing this the women's autonomy model. The combination of the importance of women's absolute earnings and their non-linear relationship with housework hours across the distribution of those earnings may account for the continuing evidence of gender deviance neutralisation reported in the literature (Killewald and Gough 2010).

In mixed-methods research, the autonomy model found some support in interviews with UK professional/managerial women who earned more than their male partner. These interviews revealed that, although the majority described themselves as more likely to take responsibility for housework, they reported a significantly less traditional division of domestic labour than other women, and did not report that this responsibility was part of any effort to neutralise gender deviance. Indeed, it appeared that these women were simultaneously undoing gender (Deutsch 2007; Risman 1998) and doing gender. In situations where they believed that the division of labour was unfair, they contested their male partners' performance of housework (Benjamin and Sullivan 1999; Lyonette and Crompton 2015).

To summarise, there is evidence that economic bargaining plays a significant role in couples' decisions about the division of housework, but that this effect is at least mediated by gender. It is also clear that the processes of negotiation and bargaining are more nuanced, and involve wider considerations with respect to resources and power within couples, than traditional economic bargaining theory assumes. Overall, at all levels of couple resources, women, on average, do more housework and care tasks than men - albeit with the caveat that the division of housework tends to be more equal in couples in which the woman earns more than her male partner (Sullivan and Gershuny 2016). Indeed, some influential qualitative research has focused explicitly on couples in which the division of housework and care was equal. This research showed that, both in the US and internationally, the factors that are associated with equal sharing include couples' gender ideologies (equality-friendly attitudes and willingness to defy normative assumptions of gender), as well as influences from the partners' families of 
origin, and the extent to which workplaces are structured to promote equality (Deutsch 1999; Deutsch and Gaunt 2020).

\subsection{Caring for Children; Not Unpaid 'Work'!}

The finding that caring for children is, in general, rated as much more enjoyable than doing housework implies that the motivations and processes involved when couples are negotiating child-care responsibilities differ from those involved when they are negotiating housework (Sullivan 2013). While housework is regarded as an undesirable activity, caring - and, in particular, caring for children - falls into a different category of experiences that are perceived as being, at least in some aspects, enjoyable and rewarding. This distinction is also necessary because it is gendered: research has shown that women tend to do more of the less enjoyable tasks within the general category of child care (e.g., changing nappies and preparing routine meals), while their male partners are more likely to be involved in more interactive or fun activities with children (e.g., Bianchi et al. 2006; Roeters et al. 2009).

There is ample evidence that the amount of time parents devote to child care has been increasing, and these findings are discussed in greater detail in the following section. This trend has been attributed to changes in the meaning and nature of child care, with a growing emphasis, in particular among the more highly educated middle classes, on more caring fathering practices and father participation in child-related activities (Gracia and Ghysels 2017; Kalil et al. 2012; Sayer et al. 2004). Bianchi et al. (2006) suggested that parents seek ways to maximise the time they spend with their children by including children in their own leisure time. The increase in recreative child care is particularly relevant to highly educated parents who may seek to expose children to activities and programmes designed to prepare them for college or career opportunities (Ramey and Ramey 2010). By investing more in such behaviours, highly educated parents promote processes of capital formation among their children, thereby reinforcing existing differentials in human and cultural capital (Lareau 2011).

It is also clear that the process of becoming a parent is a key gendered landmark in the longitudinal process of decision making with regard to the division of domestic labour and care (e.g., Dribe and Stanfors 2009). The birth of a first child often leads to a marked shift in domestic responsibilities, even among couples whose ideological orientation is gender-equal. This process and its effects have been documented across Europe in a recent longitudinal qualitative study of mainly middle-class, dual-earner couples before and after the birth of their first child (Grunow and Evertsson 2016, 2019). The study found that a 'significant share' of the parents who had planned to divide responsibilities equally after the birth ended up with a more traditional division of housework and care, largely due to the combined influence of the social policy context and the normative gender culture in which they were living (Grunow and Evertsson 2016, 2019).

\section{CROSS-SECTIONAL DIFFERENCES IN AN INTERNATIONAL CONTEXT}

Reviews published across successive decades have summarised research on individual and couple differences in the time women and men spend on housework and child care (Bianchi et al. 2012; Coltrane 2000 for the 1990s; Lachance-Grzela and Bouchard 2010 for the 2000s). 
In addition to the focus on individual and relative spousal income elucidated in the theoretical perspectives outlined above, educational level has been consistently found identified as among the most significant influences on the division of labour (ibid.). Moreover, for the reasons referred to in the section above, the relationships found between education and housework and education and child care differ. In general, the higher a woman's level of education, the less housework she does, while the opposite relationship is observed among men. In contrast, a strong positive relationship between child care and educational level has been reported for both men and women.

Because the overwhelming focus of the early literature on this topic was on white, heterosexual couples, differences in relation to race and sexuality have been far less studied, although the body of research on how the performance of various household and care tasks differs by race/ethnicity and sexuality has been growing (Evertsson et al. in this volume). Findings have been varied, but it is clear that in the area of race/ethnicity, some black and ethnic minority fathers and men do more child-care tasks and housework than their white counterparts (e.g., Cabrera et al. 2011 for the US; Kan and Laurie 2016 for the UK). Research on same-sex couples also presents an interesting challenge for existing theoretical models, which are based on a normative model of heterosexual spouses that plugs into the wider framework of gender inequality. There is no reason to directly transpose this model onto same-sex couples, and, indeed, there is evidence that same-sex couples share child care and housework more equally than heterosexual couples (Evertsson et al. in this volume; Goldberg 2013; Kurdek 2007).

National social policies relating to women's employment, parental leave, and early child-care provision have also been shown to constrain or facilitate the promotion of gender equality in unpaid work and care in various ways (e.g., Craig and Mullan 2010; Cooke and Baxter 2010; Davis and Greenstein 2013; Fuwa and Cohen 2007; Hook 2010; Knudsen and Waerness 2007; van der Lippe and van Djik 2001). The development of multi-level statistical models has made it possible to distinguish between the contributions of individual-level and context (country or welfare regime)-level variables. Overall, this body of research clearly supports the argument that the institutional settings that govern welfare policies and provisions strongly influence the individual-level factors that determine the gender division of housework and care (Treas and Drobnic 2010). For example, in relation to housework, such analyses have found that women do less housework and men do more housework in countries that have (a) higher levels of full-time employment among women, (b) greater provision of publicly funded child care, (c) relatively short paid maternal leave periods, and (d) more egalitarian gender attitudes.

\section{INTERNATIONAL TRENDS USING TIME USE DIARY DATA}

In this section, I focus on cross-national changes in the time women and men spend on housework and child care based on time use diary data. For large-scale quantitative analyses of the organisation and the division of the activities of daily life, including housework and care, time use diary surveys are considered the 'gold standard' (Cornwell et al. 2019). As time use diaries ask respondents to record continuous sequences of their activities across the day, they provide the most reliable estimates of the time people spend on different activities. Direct questions about time in conventional questionnaire surveys - for example, 'How many hours did you spend in your job last week?' - are prone to error, because people are not used to making 
these sorts of summations. On the other hand, people are relatively used to providing the sort of sequential narratives that diaries contain; and it turns out that most people can record quite detailed and accurate accounts of their days using this approach. These sequential narratives of large numbers of distinct activities can then be classified for the purposes of analysis into larger groups of activities (e.g., paid work, leisure, and unpaid work).

Many time use diary surveys also ask respondents to record where they were when they were engaged in specific activities, who they were with, and other aspects of their instantaneous experiences, such as the enjoyment or stress associated with a particular episode of time. Time use diaries are typically collected across one or (preferably) a few days a week, and are completed by individuals or (preferably) all members of households. As there are now more than 100 nationally representative diary studies of developed and less developed countries available for study, both cross-national and comparative analyses of historical time use trends are possible. The development of these cross-time and cross-national series of time use data since the 1960s has enabled researchers to conduct large-scale analyses of international trends in, among other things, the gender division of household labour and care. The most extensive comparative information we have on international trends in domestic work and care come from the Multinational Time Use Survey; an archive of time use survey data that have been harmonised to enable comparisons across time and countries (Gershuny and Fisher 2013).

Whether meaningful change has occurred in the gender division of domestic labour and care over the past half-century has been a contested question since research on this topic began. The idea that progress towards a convergence in the amount of time women and men spend doing housework and care has 'stalled' has become popular (e.g., Cotter et al. 2011; England 2010; for media commentary following this research see Cohen 2014 and Coontz(2013). Research using time use data has reported a widespread decline in the amount of time women are spending on housework; with some corresponding, albeit much smaller, increases in the amount of time men are spending on housework, and rather larger increases in the amount of time men are spending on child care, across the countries of North America, Europe, and Australia (Bianchi et al. 2006; Gauthier et al. 2004; Gershuny 2000; Sullivan et al. 2018). Analysing these trends using a multi-level model of housework time that nests individuals within country-years, and that controls for demographic and socio-economic variables, Altintas and Sullivan (2018) showed that although there has been a relatively steep decline over time in gender inequality in the time spent on housework in countries that are still relatively gender-unequal, this trend has attenuated over time in countries where the time men and women spend on housework has already become more equal (see also Geist and Cohen 2011 for an earlier version of this argument). This is likely to be the effect of, in the first instance, steep declines in the time women spend on housework associated with their increasing move into the primary labour force, followed by a slowing in the trend towards gender equality through men's failure to 'make up the gap' by increasing the time they spend on housework. This apparent support for the idea that, in certain countries, progress towards gender convergence has 'stalled' illustrates the challenges involved in achieving the 'second half' of the gender revolution, as described in Goldscheider et al. (2015). In the first half of this revolution, women move into paid work, while in the second half, the division of labour becomes more equal, including in the sphere of unpaid work and care. Overall, these findings point to a long-term cross-national process of stuttering progress towards gender equality in which men's contributions to housework are slowly increasing, while women's are dramatically decreasing, and both mothers and fathers are increasing their child-care time. 


\section{FOCUS ON FATHERS: A KEY COMPONENT OF CHANGE?}

We know that the time men spend on housework has been increasing only rather slowly over recent decades, while their contributions to child care have been increasing more rapidly. If we want to understand and promote progressive change towards gender equality, this latter trend provides us with an opportunity to identify the factors that underlie it, which could, in turn, provide us with a push towards achieving the 'second half' of the gender revolution. Child care performed by fathers has, therefore, become an important focus of both academic research and popular interest. As I noted in the section above, there has been a clear, across-the-board increase in the amount of time fathers spend on care in the industrialised countries for which we have time use data series. However, these overall trends conceal significant heterogeneity at both the individual level, according to men's educational attainment; and the institutional level, according to social policy regime type.

In relation to the educational attainment of men, it has been argued that the increases we observe in the care provided by fathers are in line with a growing emphasis on caring fathering practices. Higher educational attainment is associated not only with more egalitarian gender ideologies, but also with greater investment in 'developmental' activities for children (which may have the effect of reinforcing existing differentials in human and cultural capital, as more highly educated parents are able to promote processes of capital formation among their children: Altintas 2016; Lareau 2011; Ramey and Ramey 2010). A study comparing married/ cohabiting fathers of young children in the gender-traditional countries of Southern Europe with their counterparts in other developed countries found that, overall, being college-educated has a stronger positive effect over time on fathers' contributions, and that this relationship proved to be the strongest in the more gender-traditional countries (Sullivan et al. 2014). This evidence of a 'catch-up' effect among educated fathers in countries where the division of labour between women and men has been most traditional lends support to the idea that there has been a 'social diffusion' effect that has led to the spread of ideologies that promote the egalitarian division of domestic labour and care (Esping-Andersen and Billari 2015). This observation also resonates with the findings of Altintas and Sullivan (2016).

Altintas and Sullivan (2016) added an institutional-level dimension to these trends by focusing on fathers of children under age five living in different clusters of countries defined by their social policy contexts (see Esping-Andersen 2009). While the time spent on child care by these fathers increased significantly in all policy clusters over the 40 -year study period, the gap between fathers in the Nordic and in the Corporatist (continental European) policy clusters widened over the period, with the Nordic fathers moving ahead. On the other hand, fathers from the Liberal (Anglophone) policy cluster showed the most rapid increase, and had almost caught up with the Nordic fathers by the end of the period. The trends in the time spent on core housework varied, with only minor increases being observed among fathers from both the Liberal and the Corporatist policy clusters. Particularly striking was, however, the 'catch-up' effect found among fathers from the Southern (Mediterranean) cluster of countries, such that the gap in the time spent on housework between these fathers and those from the Liberal and Corporatist clusters had practically closed by the end of the 40 -year period. To summarise, the time fathers spent on child care increased substantially in all countries, but the gap between the Nordic and the Liberal and the Southern countries narrowed, while fathers in Corporatist countries lagged behind. The time fathers spent on housework also increased over the study period, but to a lesser extent, except in the Nordic countries. Thus, it appears that fathers from 
the Nordic countries continued to 'set the bar', with fathers from the Southern policy cluster 'catching up'.

\section{CHALLENGES FOR POLICY}

Progress towards gender equality in housework and care is related to progress in the overall division of labour between women and men. Most of the move towards gender convergence in the domestic sphere has occurred because of the reduction in the time women spend on traditionally feminine-defined and less enjoyable domestic tasks such as cleaning. Nevertheless, the long-term trends suggest that men's involvement is gradually changing, with men taking on more child care, which is considered the most enjoyable of the domestic and care tasks.

The progressive change argument is supported by time use data showing that the time women spend on housework has declined considerably and has increased slightly among men, while the time spent on child care has increased for both. The recent introduction and/ or expansion of paternal leave regulations in many European countries also signals a shift at the institutional level in acceptance of shared parental responsibilities, even though this process is halting, and does not always have an immediate impact on behaviour (O'Brien and Wall 2017). In addition, there is evidence of relatively widespread changes in related gender attitudes. International Social Survey Programme data show that attitudes towards gender equality are continuing to change among younger cohorts of men. For example, across the Anglo-liberal countries, the Nordic countries, the Mediterranean countries, Japan, and the Corporatist countries of Central Europe, we see declines over decades in the percentage of younger men agreeing with the statement that 'A man's job is to earn money; a woman's job is to look after the home and family'. In the Deloitte Millennial Survey of 2018, which included responses from more than 10,000 millennials across 36 countries, 48 per cent of millennial fathers said they would be willing to take a pay cut to achieve a better work-life balance. In the UK, seven out of 10 millennial fathers said they would consider their child-care responsibilities before taking a new job or promotion (Deloitte Millennial Survey 2018).

On the other hand, there is also some evidence for a stalling, or levelling off, of the trend towards gender equality in household labour and care in certain countries in which the process of gender convergence is more advanced. Whether this represents a ceiling beyond which gender convergence cannot continue without widespread institutional change remains to be seen. It could, however, also be argued that progressive change should always be regarded as a long-term, uneven process, and that large-scale changes are unlikely to occur over the course of just a few decades. Those at the forefront of movements promoting change will always face forces of conservatism who wish to preserve the status quo. Change may be stalled or even reversed by the deliberate resistance of political bodies, social movements, or institutions, such as movements associated with the growth of the populist new right, and family movements in the US that seek to severely restrict or ban abortion.

In terms of policy responses, there is a need for measures that support genuine work-family flexibility, while also providing parents with easy access to high-quality, affordable early child-care facilities. By making it easier for both partners to return to work after having a child, such measures can significantly enhance gender equality. Introducing paternity leave has also proved effective in encouraging fathers to spend time caring for their children, particularly when leave benefits involve meaningful periods of time, and are provided to fathers on a 'use 
it or lose it' basis (Brandth and Kvande 2019). However, these structural transformations are unlikely to happen as long as many workplaces are still dominated by a traditional, patriarchal management culture that rewards employees for working long fixed hours, being constantly available, and always prioritising work over family. A business culture that allows parents to work shorter or more flexible hours, enabling them to take time off when their children are sick (assisting them to flexibly make up the hours lost, for example from home), would go a long way to help overcome some of the hurdles in the path of gender equality in the division of labour.

\section{CONCLUSION AND CHALLENGES FOR FUTURE RESEARCH}

The challenge for future research is to understand how progressive change happens across time; i.e., to identify which factors promote it, and which factors hinder it. This will require a combination of existing methodologies with new longitudinal dimensions of explanation based on the trajectories of individuals and couples. The longitudinal dimension is represented in statistical modelling by life course analysis; i.e., the analysis of the life course trajectories of individuals, which can now be extended to multi-level modelling for longitudinal data. While quantitative research using longitudinal modelling to investigate these dynamics is a relatively recent innovation, it is likely to make an increasingly important contribution to the field. For example, recent research has used panel data to investigate how the gender division of domestic labour and care between partners is interconnected across their partnership trajectories, and how these trajectories are linked to events such as the birth of a child. The results of these studies suggest that gender-egalitarian attitudes and behaviour - reflected in, for example, the take-up by fathers of parental leave and flexible working - have life-long positive effects on gender equality (e.g., Killewald and García-Manglano 2016; Nitsche and Grunow 2016; Schober and Zoch 2019). Qualitative longitudinal studies that trace the same individuals and couples through time - as in the example of Grunow and Evertsson $(2016,2019)$ mentioned above - are also likely to make increasing contributions to our understanding of the micro processes involved in progressive change.

The increase in research focusing on longitudinal processes has influenced the recent development of a theoretical model that has drawn attention to the slow, cross-generational processes involved in achieving meaningful changes over time. The model of 'lagged generational change', advanced in Sullivan et al. (2018), takes a multi-level perspective that combines the idea of the recursive influence of the micro (interactional) and macro (institutional) levels with a longitudinal dimension based on individual and couple trajectories. In the specific configuration associated with the gendered division of unpaid work and care, this model links early gender socialisation in the family of origin (important in Deutsch's 1999 and 2020 research referred to above) to peer and spousal interactions in later life (as in the bargaining and marital power literature); all embedded within a wider context of gender ideologies, regulatory systems, and material constraints. In its current form, this model is relatively static, as it is designed to show why change happens only slowly. However, recent studies of the kind referred to above can help to elucidate the points at which dynamic elements of change may be introduced into it. For example, where a child has more liberal parents committed to non-normative gender practices, or where spouses share a common ideological commitment 
to equality, or where a workplace is organised to cope flexibly with parental commitments, or where a wider shift in social policy increases the flexibility of parental leave benefits. All of these factors have been shown to be influential in promoting progressive change, and the elucidation of the processes involved in facilitating them is likely to be the major challenge facing future research in this area.

\section{NOTE}

1. This wider grouping still has its uses; for example, in the demonstration of the total value of all unpaid domestic and care work to national economies, estimated for the UK at over 25 per cent of the total value of GDP (Suh and Payne 2019).

\section{REFERENCES}

Altintas, E. (2016), 'The widening education gap in developmental, child care activities in the United States, 1963-2013', Journal of Marriage and Family, 78, 26-42. doi:10.1111/jomf.12254.

Altintas, E. and O. Sullivan (2016), 'Fifty years of change updated: Cross-national gender convergence in housework', Demographic Research, 35, 455-70. doi:10.4054/DemRes.2016.35.16.

Altintas, E. and O. Sullivan (2018), 'Trends in fathers' contribution to housework and child care under different welfare policy regimes', Social Politics, 24 (1), 81-108. doi:10.1093/sp/jxw007.

Becker, G. (1981), A Treatise on the Family, Cambridge, MA: National Bureau of Economic Research.

Benjamin, O. and O. Sullivan (1999), 'Relational resources, gender consciousness and possibilities of change in marital relationships', Sociological Review, 47 (4), 494-820. doi:10.1111/1467-954X .00196 .

Berk, S.F. (1985), The Gender Factory: The Apportionment of Work in American Households, New York: Plenum. doi:10.1007/978-1-4613-2393-8.

Bianchi, S.M., J.P. Robinson, and M.A. Milkie (2006), Changing Rhythms of American Family Life, New York: Russell Sage Foundation.

Bianchi, S.M., L.C. Sayer, M.A. Milkie, and J.P. Robinson (2012), 'Housework: Who did, does or will do it, and how much does it matter?', Social Forces, 91, 55-63. doi:10.1093/sf/sos120.

Bittman, M., P. England, N. Folbre, L. Sayer, and G. Matheson (2003), 'When does gender trump money? Bargaining and time in household work', American Journal of Sociology, 109, 186-214. doi: $10.1086 / 378341$.

Blood, R.O. and D.M. Wolfe (1960), Husbands and Wives: The Dynamics of Married Living, New York: Free Press. doi:10.1086/223068.

Brandth, B. and E. Kvande (2019), 'Fathers' sense of entitlement to ear-marked and shared parental leave', Sociological Review, 67, 1154-69. doi:10.1177/0038026118809002.

Brines, J. (1994), 'Economic dependency, gender and the division of labor at home', American Journal of Sociology, 100, 652-88. doi:10.1086/230577.

Cabrera, N.J., S.L. Hofferth, and S. Chae (2011), 'Patterns and predictors of father-infant engagement across race/ethnic groups', Early Childhood Research Quarterly, 26, 365-75. doi:10.1016/j.ecresq .2011.01.001.

Cohen, P.N. (2014), 'How can we jump-start the struggle for gender equality?', New York Times Opinion Pages, accessed 23 November 2019 at opinionator.blogs.nytimes.com/2013/11/23/how-can-we-jump -start-the-struggle-for-gender-equality/.

Coltrane, S. (2000), 'Research on household labour: Modeling and measuring the social embeddedness of routine family work', Journal of Marriage and Family, 62, 1208-33. doi:10.1111/j.1741-3737 .2000.01208.x.

Cooke, L.P. and J. Baxter (2010), 'Families in international context: Comparing institutional effects across Western societies', Journal of Marriage and Family, 75, 516-36. doi:10.1111/j.1741-3737 .2010.00716.x. 
Coontz, S. (2013), 'Why gender equality stalled', New York Times Sunday Review, 16 February.

Cornwell, B., J. Gershuny, and O. Sullivan (2019), 'The sociology of time use and time structure', Annual Review of Sociology, 45, 301-20. doi:10.1007/978-1-349-20869-2 13.

Cotter, D., J.M. Hermsen, and R. Vanneman (2011), 'The end of the gender revolution? Gender role attitudes from 1977 to 2008', American Journal of Sociology, 117, 259-89. doi:10.1086/658853.

Craig, L. and K. Mullan (2010), 'Parenthood, gender and work-family in the United States, Australia, Italy, France and Denmark', Journal of Marriage and Family, 72, 1344-61. doi:10.1111/j.1741-3737 .2010.00769.x.

Davis, S.N. and T.N. Greenstein (2013), 'Why study housework? Cleaning as a window into power in couples', Journal of Family Theory and Review, 5, 63-71. doi:10.1111/jftr.12004.

Deloitte Millennial Survey (2018), ‘Millennials disappointed in business, unprepared for Industry'. www .deloitte.com/MillennialSurvey.

Deutsch, F.M. (1999), Halving It All: How Equally Shared Parenting Works, Cambridge, MA: Harvard University Press.

Deutsch, F.M. (2007), 'Undoing gender', Gender and Society, 21, 106-27. doi:10.1177/ 0891243206293577.

Deutsch, F.M. and R. Gaunt (eds) (2020), Creating Equality at Home: How 25 Couples around the World Share Housework and Child Care, Cambridge: Cambridge University Press.

Dribe, M. and M. Stanfors (2009), 'Does parenthood strengthen a traditional household division of labor? Evidence from Sweden', Journal of Marriage and Family, 71, 33-45. doi:10.1111/j.1741-3737.2008 .00578.x.

England, P. (2010), 'The gender revolution: Uneven and stalled', Gender and Society, 24, 149-66. doi: $10.1177 / 0891243210361475$.

Esping-Andersen, G. (2009), The Incomplete Revolution, Cambridge: Polity Press. doi:10.1017/ S0047279410000085.

Esping-Andersen, G. and F.C. Billari (2015), 'Re-theorizing family demographics', Population and Development Review, 41, 1-31. doi:10.1111/j.1728-4457.2015.00024.x.

Fuwa, M. and P.N. Cohen (2007), 'Housework and social policy', Social Science Research, 36, 512-30. doi:10.1016/j.ssresearch.2006.04.005.

Gauthier, A.H., T.M. Smeeding, and F.F. Furstenberg, Jr. (2004), 'Are parents investing less time in children? Trends in selected industrialized countries', Population and Development Review, 30 (4), 647-72. doi:10.1111/j.1728-4457.2004.00036.x.

Geist, C. and P.N. Cohen (2011), 'Headed towards equality? Housework change in comparative perspective', Journal of Marriage and Family, 73, 832-44. doi:10.1111/j.1741-3737.2011.00850.x.

Gershuny, J. (2000), Changing Times: Work and Leisure in Post-Industrial Society, Oxford: Oxford University Press. doi:10.2307/3089489.

Gershuny, J. (2019), 'Time and enjoyment' in J. Gershuny and O. Sullivan (eds), What We Really Do All Day, Insights from the Centre for Time Use Research, London: Penguin Books (Pelican).

Gershuny, J. and K. Fisher (2013), The Multinational Time Use Study, Oxford: Centre for Time Use Research at the University of Oxford. doi:10.1007/978-94-007-0753-5 3949.

Goldberg, A.E. (2013), “"Doing” and "undoing” gender: The meaning and division of housework in same-sex couples', Journal of Family Theory and Research, 5, 85-104. doi:10.1111/jftr.12009.

Goldscheider, F., E. Bernhardt, and T. Lappegård (2015), 'The gender revolution: A framework for understanding changing family and demographic behavior', Population and Development Review, 41 (2), 207-39. doi:10.1111/j.1728-4457.2015.00045.x.

Gracia, P. and J. Ghysels (2017), 'Educational inequalities in parental care time: Cross-national evidence from Belgium, Denmark, Spain, and the United Kingdom', Social Science Research, 63, 166-80. doi: 10.1016/j.ssresearch.2016.09.016.

Greenstein, T.N. (2000), 'Economic dependence, gender, and the division of labor in the home, a replication and extension', Journal of Marriage and the Family, 62, 322-35. doi:10.1111/j.1741-3737 .2000.00322.x.

Grunow, D. and M. Everttson (2016), Couples' Transitions to Parenthood: Analysing Gender and Work in Europe, Cheltenham, UK and Northampton, MA, USA: Edward Elgar Publishing. doi:10.1111/ spol.12461. 
Grunow, D. and M. Everttson (eds) (2019), New Parents in Europe: Work-Care Practices, Gender Norms and Family Policies, Cheltenham, UK and Northampton, MA, USA: Edward Elgar Publishing. doi:10.4337/9781788972970.

Gupta, S. (2007), 'Autonomy, dependence or display? The relationship between married women's earnings and housework', Journal of Marriage and Family, 69, 399-417. doi:10.1111/j.1741-3737 .2007.00373.x.

Gupta, S. and M. Ash (2008), 'Whose money, whose time? A nonparametric approach to modeling time spent on housework in the United States', Feminist Economics, 14, 93-120. doi:10.1080/ 13545700701716664.

Hochschild, A.R. and A. Machung (1989), The Second Shift: Working Parents and the Revolution at Home, Berkeley, CA: University of California Press. doi:10.1086/229595.

Hook, J.L. (2010), 'Gender inequality in the welfare state: Sex segregation in housework, 1965-2003', American Journal of Sociology, 115, 1480-523. doi:10.1086/651384.

Kalil, A., R. Ryan, and M. Corey (2012), 'Diverging destinies: Maternal education and the developmental gradient in time with children', Demography, 49, 1361-83. doi:10.1007/s13524-012-0129-5.

Kan, M.Y. and H. Laurie (2016), 'Who is doing the housework in multicultural Britain?', Sociology, 62 (2), 335-58. doi:10.1177/0038038516674674.

Killewald, A. and J. García-Manglano (2016), 'Tethered lives: A couple-based perspective on the consequences of parenthood for time use, occupation, and wages', Social Science Research, 60, 266-82. doi:10.1016/j.ssresearch.2016.03.007.

Killewald, A. and M. Gough (2010), 'Money isn't everything: Wives' earnings and housework time', Social Science Research, 39, 987-1003. doi:10.1016/j.ssresearch.2010.08.005.

Knudsen, K. and K. Waerness (2007), 'National context and spouses' housework in 34 countries', European Sociological Review, 24, 97-113. doi:10.1093/esr/jcm037.

Kurdek, L.A. (2007), 'The allocation of household labour by partners in gay and lesbian couples', Journal of Family Issues, 28, 132-48. doi:10.1177/0192513X06292019.

Lachance-Grzela, M. and G. Bouchard (2010), 'Why do women do the lion's share of housework: A decade of research', Sex Roles, 63, 767-80. doi:10.1007/s11199-010-9797-z.

Lareau, A. (2011), Unequal Childhoods: Class, Race, and Family Life, 2nd edition, Berkley, CA: University of California Press.

Lundberg, S. and R.A. Pollak (1996), 'Bargaining and distribution in marriage', Journal of Economic Perspectives, 10, 139-58. doi:10.1257/jep.10.4.139.

Lyonette, C. and R. Crompton (2015), 'Sharing the load? Partners' relative earnings and the division of domestic labour', Work, Employment and Society, 29 (1), 23-40. doi:10.1177/0950017014523661.

Morris, L. (1985), 'Renegotiation of the domestic division of labour in the context of redundancy', in B. Roberts et al. (eds), New Approaches to Economic Life, Manchester: Manchester University Press. doi:10.1007/978-1-349-18088-2_10.

Nitsche, N. and D. Grunow (2016), 'Housework over the course of relationships: Gender ideology, resources, and the division of housework from a growth curve perspective', Advances in Life Course Research, 29, 80-94. doi:10.1016/j.alcr.2016.02.001.

O'Brien, M. and K. Wall (2017), 'Fathers on leave alone: Setting the scene', in M. O'Brien and K. Wall (eds), Comparative Perspectives on Work-Life Balance and Gender Equality: Fathers on Leave Alone, London: Springer, pp. 1-10.

Oakley, A. (1974), The Sociology of Housework, London: Martin Robinson.

Ramey, G. and V.A. Ramey (2010), 'The rug rat race', Brookings Papers on Economic Activity, Spring, 129-99. doi:10.3386/w15284.

Risman, B. (1998), Gender Vertigo, New Haven, CT: Yale University Press. doi:10.1176/appi.ps.51.2.256.

Roeters, A., T. Van de Lippe, and E. Kluwer (2009), 'Parental work demands and the frequency of child-related routine and interactive activities', Journal of Marriage and Family, 71, 1193-204. doi: 10.1111/j.1741-3737.2009.00663.x.

Sayer, L.C., A.H. Gauthier, and F.F. Fürstenberg, Jr. (2004), 'Educational differences in parents' time with children: Cross-national variations', Journal of Marriage and Family, 66, 1152-69. doi:10.1111/ j.0022-2445.2004.00084.x. 


\section{Research handbook on the sociology of the family}

Schober, P.S. and G. Zoch (2019), 'Change in the gender division of domestic work after mothers or fathers took leave: Exploring alternative explanations', European Societies, 21 (1), 158-80. doi:10 $.1080 / 14616696.2018 .1465989$.

Sorensen, A. and S. McLanahan (1987), 'Married women's economic dependency, 1940-1980', American Journal of Sociology, 93, 659- 87. doi:10.1086/228792.

Suh, J. and C. Payne (2019), 'Unpaid work matters: Valuing household production time' in J. Gershuny and O. Sullivan (eds), What We Really Do All Day, Insights from the Centre for Time Use Research, London: Penguin Books (Pelican).

Sullivan, O. (2013), 'What do we learn about gender by analyzing housework separately from child care? Some considerations from time-use evidence', Journal of Family Theory and Review, 5, 72-84. doi: $10.1111 /$ jttr.12007.

Sullivan, O. and J. Gershuny (2016), 'Relative human capital and the performance of housework within couples, a longitudinal perspective', European Sociological Review, 32, 864-80. doi:10.1093/esr/ jcw04.

Sullivan, O., F.C. Billari, and E. Altintas (2014), 'Fathers' changing contributions to child care and domestic work in very low fertility countries: The effect of education', Journal of Family Issues, $\mathbf{3 5}$, 1048-65. doi:10.1177/0192513X14522241.

Sullivan, O., J. Gershuny, and J.P. Robinson (2018), 'Stalled or uneven gender revolution? A long-term processual framework for understanding why change is slow', Journal of Family Theory and Review, 10 (1), 1-17. doi:10.1111/jftr.12248.

Treas, J. and S. Drobnic (2010), Dividing the Domestic: Men, Women, and Household Work in Cross-National Perspective, Palo Alto, CA: Stanford University Press.

Van der Lippe, T. and L. van Dijk (eds) (2001), Women's Employment in a Comparative Perspective, New York: Aldine de Gruyter.

West, C. and D.H. Zimmerman (1987), 'Doing gender', Gender and Society, 1, 125-51. doi:10.1177/ 0891243287001002002 . 